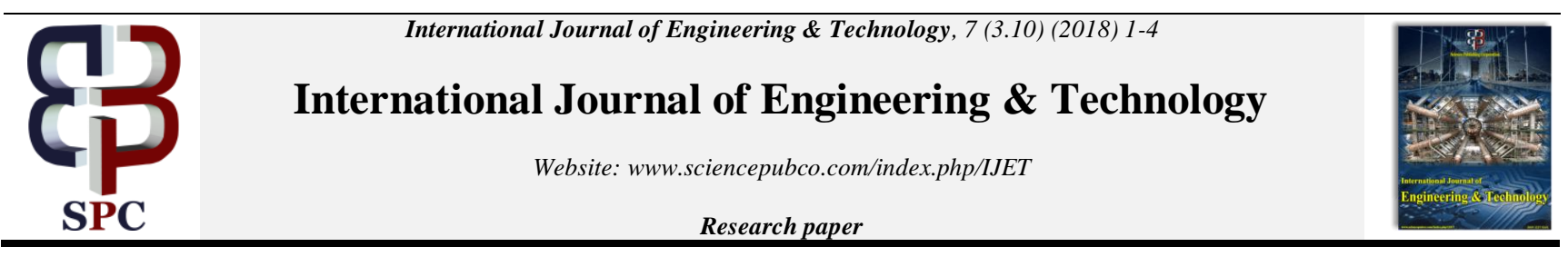

\title{
Maturing Construction Management Up The Bim Model \& Scheduling Using Primavera
}

\author{
T.Subramani ${ }^{1 *}$, A.Ammai ${ }^{2}$ \\ $1^{*}$ Managing Director, Priyanka Associates (Civil Engineers and Valuers), Salem, TamilNadu, India. \\ ${ }^{2}$ Design Engineer, KCICI PVT.Ltd., Bommidi, Dharmapuri, TamilNadu, India. \\ "Corresponding author E-mail:tsmcivil2007@gmail.com
}

\begin{abstract}
Poor hazard management is among significant difficulties confronting the construction business on issues of timely project completion. Although hazard factors are various, the nature of construction projects being inclined to changes amid execution makes it hard to satisfactorily catch chance perspectives identified with scheduling and timely project completion. Conventional 2D PC based devices don't enough use digitized calculable data, along these lines constrained in capturing construction risk. Hence, derive the benefit of prominent BIM to pass over this gap is presently being noted in growth venture management. This examination researches the utilization of BIM in managing scheduling risk of construction projects. In our study, to properly minimize the risk of schedule delay in projects; construction sequencing exercises should be satisfactorily digitized and BIM offers the total chance to integrate vital aspects of project management that management enhance scheduling risk management.
\end{abstract}

Keywords: Maturing, Construction, BIM, Scheduling, Primavera.

\section{Introduction}

Project Planning and Scheduling is a study of the basic principle and techniques of Planning and Scheduling for all type of construction projects. Subjects incorporate bar charts, critical path method, PERT, precedence networks, cost-time trade-offs, resource leveling and management, updating all type of schedules during construction, acquaintance and practice with project controls and transitional level of modernized scheduling in Primavera.

\subsection{Objective of the Research}

To provide best and clear know of the BIM concept and the way this new era can rework the construction industry market while followed.

- To analyze the BIM idea improvement. running with BIM concept of their initiatives transport and construction management?

- To discover the technological blessings, strategic gain and operational flexibility in building design idea with BIM technology had created inside the constructed surroundings in Scandinavian.

- To offer a roadmap to transfer and put into effect the version of BIM concept into the brand new production marketplace.

\section{Building Information Modeling}

This location describes what BIM era can imply to architects, engineers, contractors, facility control industries and all of the other stakeholders in preferred in the constructed surroundings. It additionally defines the roadmap on how to use it gear and the blessings it affords with the aid of helping to tell production specialists the idea to execute construction challenge workflow to the whole lifecycle of a building.

\subsection{Overview Building Information Modeling (BIM)}

In nowadays built surroundings, the maximum buzz phrase that is trending in fields of structure, engineering, creation and facility control industry is building information modeling (BIM). Even though, there are numerous documentations that suggests how BIM technology has revolutionize the constructing industry whilst architects, engineers, contractors, and facility managers uses it to do their companies.

The difference among the BIM-primarily based gadget and the cad-primarily based gadget is that, BIM - based generation can assemble entire digital virtual model which incorporates correct and relevant records wished for fabrication and construction.

- Models without behavioral aid - models that don't incorporate parametric intelligence and shortage the electricity to alter its positioning. This outcome for inaccuracy and inconsistency inside the view of the version. Changes made on such works are time ingesting and exertions intensity.

- That doesn't have the capacity to updates its dimensions modifications on one view to mirror to the others aspects of model mechanically - while these occurrences occurs it degenerate to mistakes within the version and can be intricate to find it.

- That has simplest 3-d statistics and without any object characteristics - this defines fashions that could have the capacity for photograph visualization and does no longer incorporate item level of intelligence. 


\subsection{BIM Integrated Information Model}

The platform of BIM technology, all venture stakeholders on the development mission proportion common information from the vital BIM data supply. This act fulfills the concept of BIM idea, in which there's free drift of facts and shared duties amongst included mission groups without any limitations. While inside the traditional team version, facts flows from the building proprietor to the architects and then unfold to the numerous people or trades undertaken the proposed project. This has the tendency to have communication issues amongst assignment groups and it may finally ends up affecting the general execution of the venture outcomes. Within the BIM platform, some of the activities that included teams engaged in are enhancing, extracting, taking part, updating and placing other applicable facts to the built version database. The outcomes of the mixing of undertaking teams on common database reduce value, errors, time, and promote the great of project works.

\subsection{BIM Data Exchange and Interoperability}

One of the simplest equipment associated with BIM generation concept is the capacity for records trade among diverse venture stakeholders which includes the building proprietor, architects, contractors, facility managers is interoperability. The term interoperability is defines because the method wherein a assignment facts is switch to extraordinary domain names and programs electronically for the use the mission stakeholders. In line With interoperability "is the ability to pass data between applications and for multiple applications to mutually make contributions to the work handy". Some years ago, documentprimarily based alternate formats for example dxf (drawing alternate format) and the only trade geometry file (initial photo change specification) are used to transfer 2 nd and 3-D drawing statistics between specific cad systems. On this interoperability, guide copying of challenge records outcomes to errors and this goes a long run to create inconsistency in cumulated statistics in automation. With BIM generation, constructed version contains extra included information as compare to cad documents.

\section{Application of Primavera Software}

Primavera is enterprise project portfolio management programming. It carries all type of management like task management, object management, cooperation and manage the capacities, and coordinates with different challenge software programs.

\subsection{Enterprise Project Management}

For a organization's multi-level tasks, a persistent figuring out, prioritizing and making an investment techniques have to be aligned. This may be finished with the aid of 'handling tasks as a collective portfolio' for better choices.

- Human sources are the most valuable and frequently high priced belongings. It's miles tough to maximise the productiveness and fee-effectiveness, of human sources. So in E.P.M., we've 'optimizing sources throughout agency' for proper survival.

- To reap mission fulfilment, clean and effective conversation ought to be there with expertise sharing team individuals.

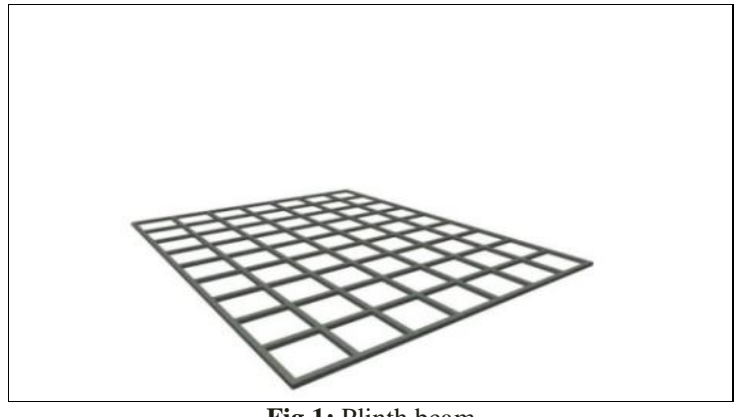

Fig.1: Plinth beam

Fig. 2 shows the column.

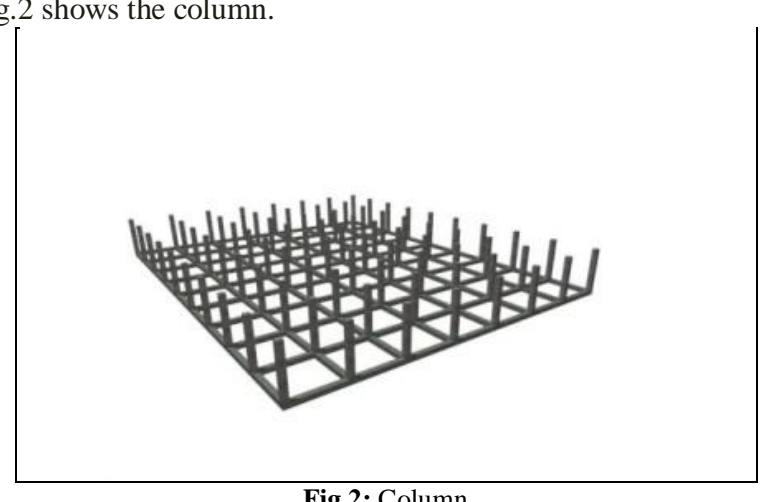

Fig.2: Column

Fig. 3 shows the floor plan.

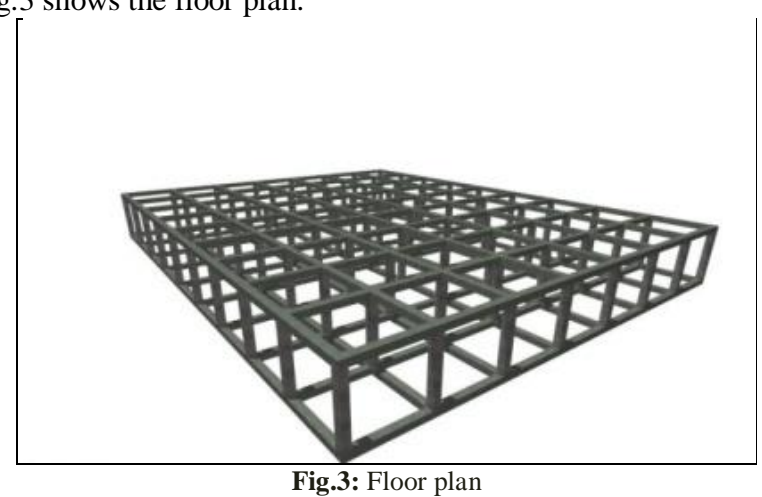

Fig. 4 shows the slab.

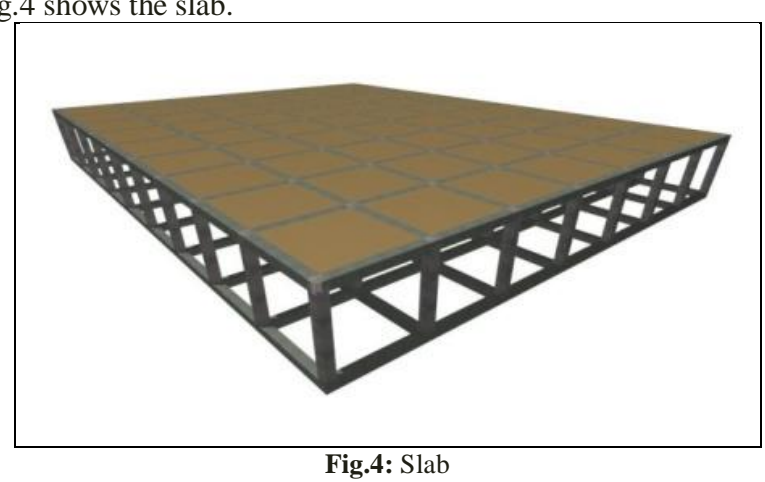

Fig. 5 shows the wall.

\section{Result and Discussion}

Fig. 1 shows the plinth beam. 


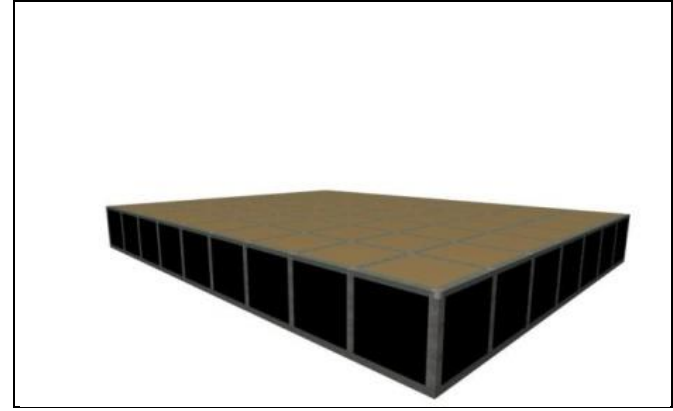

Fig.5: Wall

Fig.6 shows the full diagram.

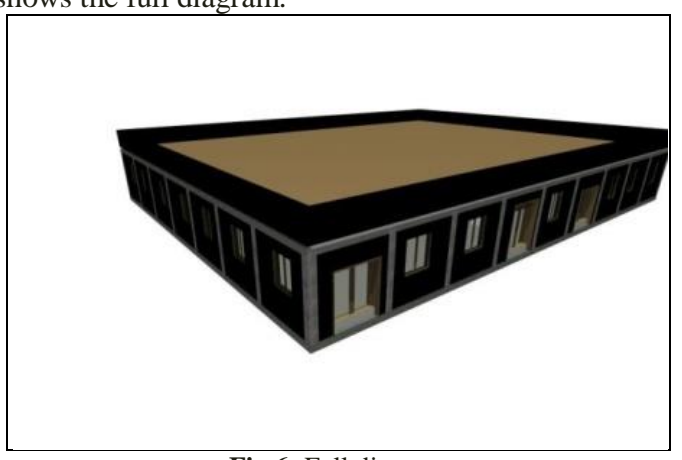

Fig.6: Full diagram

Fig. 7 shows the assigning calendar.

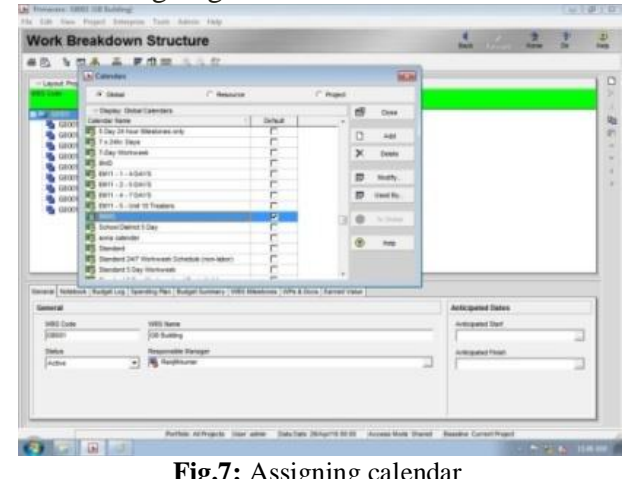

Fig.7: Assigning calendar

Fig. 8 shows the resources.

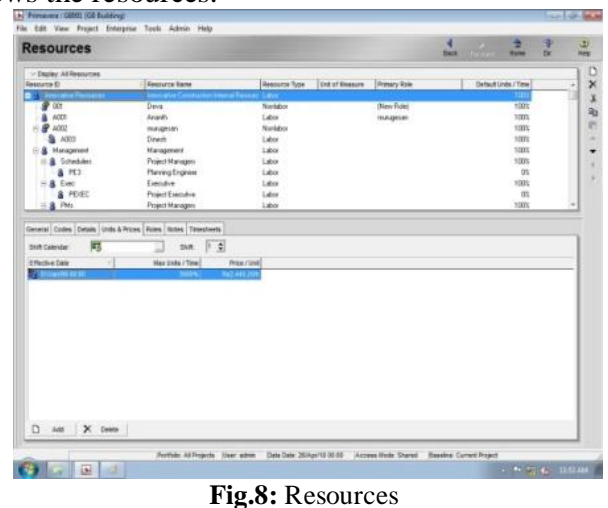

Fig.8: Resources

Fig. 9 shows the activities window 1.

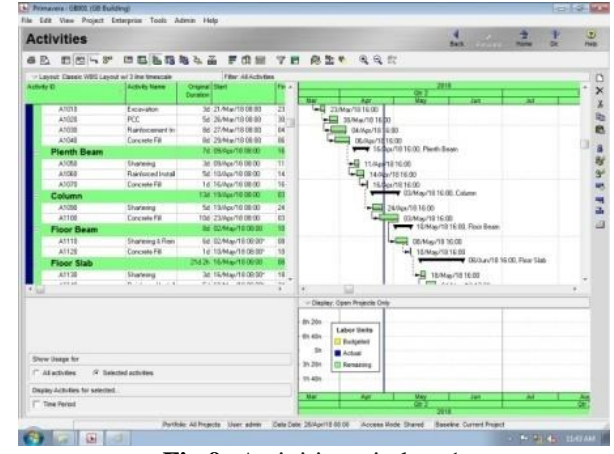

Fig.9: Activities window 1

Fig. 10 shows the activities window 2 .

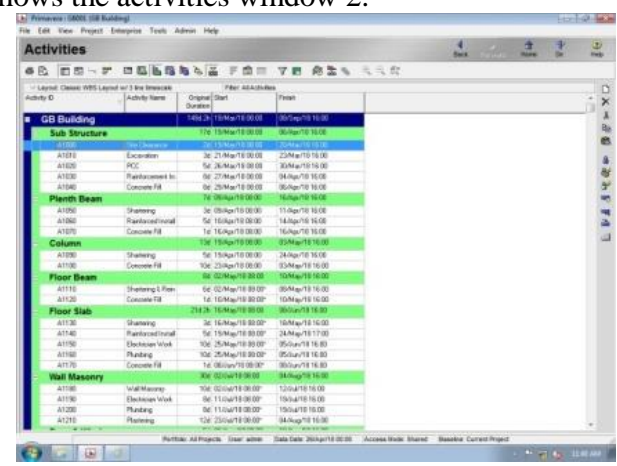

Fig.10: Activities window 2

Fig.11 shows the enterprise project structure window.

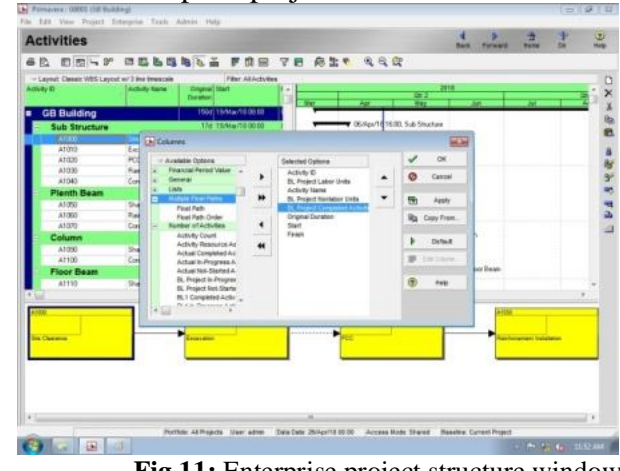

Fig.11: Enterprise project structure window

Fig.12 shows the organizational breakdown structure.

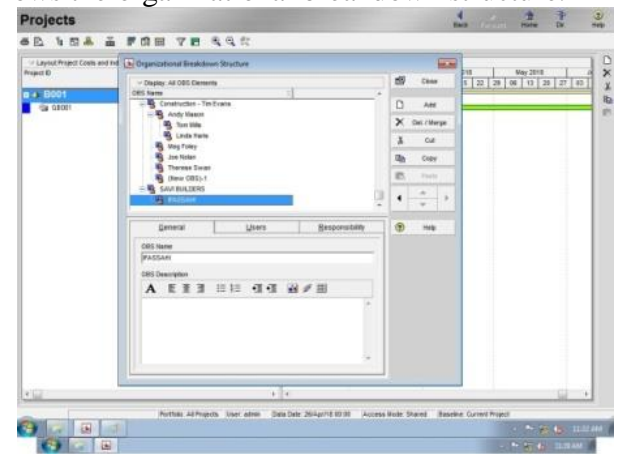

Fig.12: Organizational breakdown structure

Fig. 13 shows the project in P6 


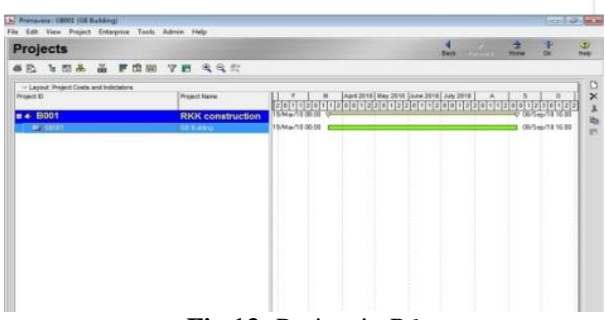

Fig.13: Project in P6

Fig.14 shows the Gantt chart in window.

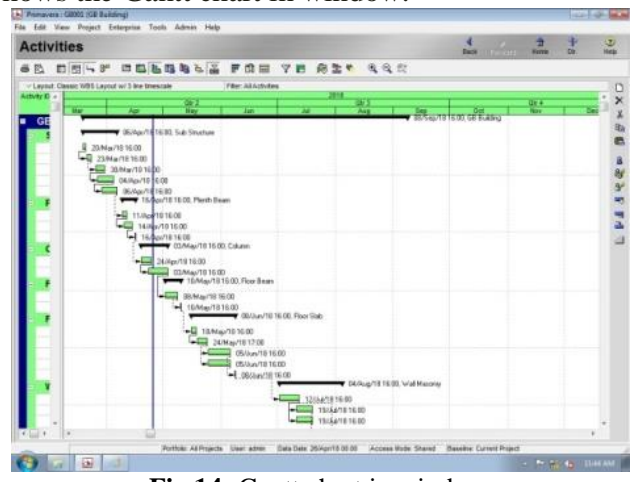

Fig.14: Gantt chart in window

\section{Conclusion}

The project contemplated six BIM usage exercises: perception, 3D coordination, cost estimation, prefabrication, construction planning and checking, and record model. The perception is for the most part the least complex utilization of a Building Information Model, for example, renderings. When the Building Information Model are delivered, the amount departures can be created to give cost estimations on a construction project. The construction industry has been known for its poor project completion by exceeding completion time. This can be described to so many reasons one of which is low project planning or scheduling. In order to properly reduce the risk of schedule delay, proper project management is required. BIM, which is an important tool in the industry, can offer the opportunity to properly manage the total risk of schedule delay. In this project, challenges associated with scheduling have been analysed. This led to the identification of common scheduling tools and whether they contain any risk management components as well as whether they can be incorporated into BIM. As the materials including but not limited to prefabricated products arrive at the job site, the planning techniques and 3D model can be combined with other BIM enabled tools to provide construction monitoring services. Based on the construction monitoring, the construction planning can be strategized.

\section{References}

[1]. T.Subramani., "Cost Estimation and Identification of Transport Infrastructure facility Projects in Salem", International Journal of Engineering and Technology, Vol.2, No.5, Pp 859 - 867,2012.

[2]. T.Subramani., P.Anitha., S.Sekar., "Health-Care Waste Management System", International Journal of Engineering Research and Applications, Vol. 4, Issue 6( Version 2), pp.255-258, 2014.

[3]. T.Subramani., N.Kanthasamy., "High End Solution For Advanced Civil Engineering Projects", International Journal of Modern Engineering Research, Volume. 4, Issue. 6 (Version 3), pp 49-53, 2014.

[4]. T.Subramani.,D.S.StephanJabasingh, J.Jayalakshmi. “Analysis Of Cost Controlling In Construction Industries By Earned Value
Method Using Primavera", International Journal of Engineering Research and Applications, Volume. 4, Issue. 6 (Version 5), pp 145 $-153,2014$

[5]. T.Subramani.T, P.T. Lishitha., M.Kavitha., "Time Overrun And Cost Effectiveness In The Construction Industry", International Journal of Engineering Research and Applications, Volume. 4 Issue. 6 (Version 5), pp 111- 116, 2014

[6]. T.Subramani. , R.Lordsonmillar., "Safety Management Analysis In Construction Industry", International Journal of Engineering Research and Applications, Volume. 4, Issue. 6 (Version 5), pp 117- 120, 2014.

[7]. T.Subramani., A.Sarkunam.A, J.Jayalakshmi. "Planning And Scheduling Of High Rise Building Using Primavera", International Journal of Engineering Research and Applications, Volume. 4, Issue. 6 (Version 5), pp 134 - 144, 2014.

[8]. T.Subramani.,P.S.Sruthi., M.Kavitha. "Causes Of Cost Overrun In Construction", IOSR Journal of Engineering, Volume. 4, Issue. 6 (Version 3), pp 1 - 7, 2014

[9]. T.Subramani, M.Sekar, " Preplanning And Scheduling Of Road Construction By Using PPM" , International Journal of Application or Innovation in Engineering \& Management (IJAIEM), Volume 4, Issue 5, pp. 234-244, 2015

[10]. T.Subramani, V.Jayaraman , " Analysis Of Construction Workers Migrate From Industries" , International Journal of Application or Innovation in Engineering \& Management (IJAIEM), Volume 4, Issue 5 , pp. $274-283,2015$

[11]. T.Subramani, S.Tamizhanban , " Supply Chain Management In Construction Site By Using SPSS Software" , International Journal of Emerging Trends \& Technology in Computer Science (IJETTCS), Volume 5, Issue 3, pp. 182-193 , 2016.

[12]. T.Subramani, S.R.Rajiv , " Improving Construction Efficiency And Productivity Of Industry Using SPSS" , International Journal of Application or Innovation in Engineering \& Management (IJAIEM) , Volume 5, Issue 5, pp. 239-250, 2016

[13]. T.Subramani, K.Chinnadurai , "Construction Management And Scheduling Of Residential Building Using Primavera" International Journal of Application or Innovation in Engineering \& Management (IJAIEM), Volume 4, Issue 5, pp. 188-198, 2015

[14]. T.Subramani, Kurian Jacob , " Analysis Of Risk, Threshold And Issues And Monitoring Schedule Of Building Construction Using PPM Software", International Journal of Emerging Trends \& Technology in Computer Science (IJETTCS), Volume 5, Issue 3, pp. 171-181, 2016

[15]. T.Subramani, M. Muhammed Ansar, S.Priyanka , " Impact Of Prefabricated Technology And Equipment On The Profitability Using Primavera " , International Journal of Emerging Trends \& Technology in Computer Science (IJETTCS), Volume 6, Issue 3, May - June 2017 , pp. 176-185 , ISSN 2278-6856.

[16]. T.Subramani, V.Annamalai , S.Priyanka , " Management Information And Communication Technology In Construction Engineering Of Structures Using Primavera " , International Journal of Emerging Trends \& Technology in Computer Science (IJETTCS), Volume 6, Issue 3, May - June 2017, pp. 186-197, ISSN 2278-6856.

[17]. T.Subramani, V.Bhaskaran Nair, A.David, B.Mohamed Ghouse, N.Siva Kumar , " A Study Of Inventory Management System In Construction Industry " , International Journal of Application or Innovation in Engineering \& Management (IJAIEM), Volume 6, Issue 5, May 2017 , pp. 304-311, ISSN 2319 - 4847. 